\title{
SOUZA, Jessé. A Elite do Atraso: Da Escravidão à Lava Jato, São Paulo: Editora Leya, 2017. 242p.
}

\author{
Marco Aurélio Barbosa ${ }^{1}$
}

*Recebido em 30/05/2018.

*Aceito em 25/06/2018.

A obra intitulada A Elite do Atraso: Da Escravidão à Lava Jato do Sociólogo Jessé Souza, editada em 2017, pretende discutir, entre vários aspectos, as elites brasileiras e como estas fazem de tola toda a sociedade, no intuito da manter e satisfazer, seus interesses manipulando ao mesmo tempo o imaginário nacional, bem como, alimentando ódio aos pobres por meio da imprensa e da manipulação da chamada classe média brasileira.

Para tanto, o autor lança um olhar heráldico, na medida em que pretende empreender uma análise que busca compreender as questões e embates simbólicos relacionados ao tema, bem como compreender seus sentidos dentro do jogo social no qual se apresentam, por outro lado, faz uma análise estratigráfica destas ideias, buscado através da extração das camadas que estão para além do verniz do olhar científico subjacentes aos conceitos investigados, desnaturar o conjunto de ideias força produzidas pela elite intelectual brasileira.

Neste sentido, faz uma análise contundente da Sociologia Brasileira, que cegamente repete os erros teóricos conceituais existentes na Sociologia Clássica Brasileira, repetida de modo irrefletido, apontando assim para um senso comum douto. Ao desconstruir este pensamento apontado como précientífico, este faz uma análise quase hagiográfica, de figuras como Gilberto Freyre, Sérgio Buarque de Holanda e Raimundo Faoro, no que toca os elementos constitutivos das teorias destes autores, que apoiadas em conceitos tais do "culturalismo conservador" presente na obra de Freyre; a ideia de homem cordial, de Buarque e do conceito de patrimonialismo presente em Faoro, que teriam criado uma projeção enviesada do que seria a identidade nacional, na medida em que suas narrativas totalizantes ao inferirem sentido ao mundo, no caso explicar o que é ser brasileiro, sua origem, etc., em resumo a noção de identidade nacional, acabam por construir um libelo do que seja a ser brasileiro.

1 Bacharel e Licenciado em Sociologia pela Universidade Federal do Paraná (UFPR); Licenciado em História pelas Faculdades Integradas "Espírita” (UNIBEM); Especialista em Relações Étnico-raciais pelo Núcleo de Estudos AfroBrasileiro da Universidade Federal do Paraná (NEAB-UFPR); Mestrando em Sociologia pela Universidade Federal do Paraná (UFPR) 
Libelo este que associa a identidade nacional ao "jeitinho brasileiro" e a uma noção de sociedade "inferior e corrupta", em relação as demais nações do mundo, que se materializa em forma de um "viralatismo". Ao tocar a questão da formação da identidade nacional Souza, realiza uma critica bastante profunda destas teorias apontando suas fragilidades teóricas.

No que Jessé Souza aponta:

Este livro foi pensado para ser uma leitura historicamente informada da conjuntura recente
brasileira. A crise brasileira atual é também e antes de tudo uma crise de ideias. Existem
ideias velhas que nos legaram o tema da corrupção na política como nosso grande problema
nacional. Isso é falso, embora, como em toda mentira e em toda fraude, tenha seu pequeno
grão de verdade. Nossa corrupção real, a grande fraude que impossibilita o resgate do Brasil
esquecido e humilhado, está em outro lugar e é construída por outras forças. São essas forças,
tornadas invisíveis para melhor exercerem o poder real, que o livro pretende desvelar. Essa é
a nossa elite do atraso. (SOUZA, 2017, p.7)

Seguindo no combate a estas ideias, o autor faz uso de uma análise empírica dos fatos, bem como, de inferências observadas na obra, “A Tolice da Inteligência Brasileira: ou como o país se deixa manipular pela elite" publicada em 2015; onde ao longo de 272 páginas alude sobre o imaginário construído social e historicamente sobre Brasil e seu povo como sociedade periférica e portanto inferior, tanto do ponto de vista cultural, social e econômico.

Buscando esquadrinhar esta construção e denunciar o seu teor ideológico, o autor realiza uma análise, grosso modo, estratigráfica do tema. Esta decomposição realizada pelo autor busca colocar em perspectiva estas noções, expondo-as como um jogo retórico, bem engendrado ao longo do processo de formação social e intelectual do Brasil contemporâneo, que tem entre vários objetivos escamotear a realidade, assim como esconder os elementos perversos de dominação existentes que permitem o domínio da sociedade por uma parcela privilegiada sobre o restante, tendo como características a naturalização deste mando, bem como, a sujeição quase fatalista das populações pobres a esta condição. Esta condição como é explicitada pelo autor e resultado de um conjunto de ideias força desenvolvidas ao longa da história intelectual do país, que se espraiam para as mais diversas áreas da vida social perpetuando este quadro crítico.

Por outro, lado o autor deixa claro que a crítica ao pensamento social brasileiro não é o "mote" desta obra, já que afirma que:

Como não quero repetir argumentos já explicitados em outros livros, muito especialmente no A tolice da inteligência brasileira, farei aqui algo distinto. Como a falsa interpretação dominante, vendida como crítica social entre nós, se baseia na efetiva negação da escravidão como nossa semente societária, vou procurar reconstruir os principais elementos da gênese escravista e procurar perceber sua influência até hoje. (SOUZA, 2017, p.13)

Desta feita, Jessé Souza busca apontar como a utilização irrefletida destas ideias, acabam por se tornar uma noção epistêmica e ontológica do brasileiro, que colonizou amplos setores da sociedade brasileira, acabando por tornar-se hegemônico e adotado tanto pela esquerda quanto, pela direita que 
se apropriam com poucas diferenças deste imaginário, fato que é exposto de modo cabal quando este ao utilizar como referencias os discursos, feitos por Deltan Dalagnol e Fernando Hadad, que apontam para os jargões do patrimonialismo, do populismo, etc., como espécie de mal de origem à contaminar a política e o Estado Brasileiro.

Rechaçando este imaginário o autor realça a fragilidade dos argumentos, apontando a corrupção como algo que não exclusivo do povo brasileiro, exemplificando através de análise comparativa nos EUA, já que este representa no ideário brasileiro uma espécie de idílio, quase uma Pindorama, na qual todas as questões e problemas sociais encontraram uma solução perfeita, que passa entre muitos aspectos por noções economicistas equivocadas, que tem no mercado e empresas privadas o antídoto para o Estado tido como corrupto.

Corrupção esta herdada da colonização portuguesa realizada por estas plagas, outro conceito firmemente desconstruído pelo autor ao trabalhar a origem do termo patrimonialismo, ao recuperar o conceito proposto por Weber e ao apontar uma apropriação e aplicação indevida do conceito por Faoro, entre outros aspectos.

Sendo assim, ao realizar a sua análise comparativa e estratigráfica o autor aponta que mesmo nações não colonizadas pelo português, como os EUA por exemplo, se acham às turras com as mesmas questões que as encontradas aqui, apontando para um elemento crucial, a escravidão, característica que de fato nos distingue. Dado que a escravidão de fato é o ponto de inflexão entre o Brasil e Portugal, já que esta não achou abrigo em terras lusitanas, sendo por outro lado, largamente utilizada em terras tupiniquins.

Ao fazer alusão a escravidão Jessé Souza, aponta a utilização banalizada deste termo, que seria de fato um conceito primordial para compreender a sociedade brasileira, já que o fim da escravidão não converteu o escravo em cidadão ou gerou a absorção deste pela sociedade, mas, o lançou nas franjas da sociedade, onde passou a compor a população empobrecida brasileira. Este fato é de suma importância, na medida em que o ódio legado aos trabalhadores escravizados ao longo do processo das transformações sociais em que se operam por meio de rupturas e permanências, sendo as primeiras frutos de mudanças profundas que levam ao abandono de estruturas socialmente arcaicas e que por conta disto perdem sua função social e o segundo caso tem a ver como elementos ou vestígios de relações sociais que não perdem a sua função, mas, antes ganham maior durabilidade na medida em que são ressignificadas ou ganham novos significados sendo então reapropriadas socialmente, o que neste caso se aplica ao conceito de escravidão.

Neste caso, o elemento subjacente e invisibilizado nos debates que tratam sobre o que seria o "arquétipo" do brasileiro e sua identidade formadora, a escravidão teria em si os elementos de hierarquização e o ódio ao escravo, que dentro das transformações ocorridas em sociedade é reapropriado como ódio ao pobre, que serve ao mesmo tempo como elemento de distinção entre a 
classe média e a população pobre chamada pelo autor de "modo provocativo de ralé". A ralé, neste caso é composta pela população pobre, branca ou negra, que sofre igualmente o ônus do léxico herdado desta relação, por outro lado é importante ressaltar que a pobreza material, não é o único elemento á caracterizá-la como tal, uma vez que tanto a falta de capitais sociais, quanto culturais reforçam a desigualdade social, assim como, a estrutura de uma sociedade extremamente excludente e, que trata de modo igual os desiguais são parte dos elementos que acentuam ainda mais esta condição.

Portanto, compreender a relação entre escravidão e sociedade e, qual o papel desta nas dinâmicas sociais, acaba por ser apontada quando autor empreende uma análise da chamada classe média, que é a classe economicamente situada entre a elite do dinheiro, os ricos, " a quem invejam" e a ralé, “a quem desprezam". A classe média é caracterizada, como uma classe privilegiada, pois, conta em sua formação com capitais sociais e culturais, os quais não estão disponíveis a "ralé" por conta de sua própria formação, advinda da herança escravocrata e de um processo civilizatório "manco" que a alçou a esta condição, entretanto como salienta o autor diversas vezes em sua obra ao salientar questões como o moralismo e a noção de meritocracia presente nas relações desta fração da sociedade como os demais grupos da sociedade. Neste particular, o autor descreve um quadro no qual é possível vislumbra as relações destes grupos bem como, as formas utilizadas por eles, para justificar seus privilégios ao afirmar:

\footnotetext{
As classes superiores, que monopolizam capital econômico e cultural, têm que justificar, portanto, seus privilégios. O capital econômico se legitima com o empreendedorismo, de quem dá emprego e ergue impérios, e com o suposto bom gosto inato de seu estilo de vida, como se a posse do dinheiro fosse mero detalhe sem importância.

A legitimação dos privilégios da classe média é distinta. Como seu privilégio é invisível pela reprodução da socialização familiar que esconde seu trabalho prévio de formar vencedores, a classe média é a classe por excelência da meritocracia e da superioridade moral. Eles servem tanto para distingui-la e para justificar seus privilégios em relação aos pobres como também em relação aos ricos. É que, se os pobres são desprezados, os ricos são invejados. Existe uma ambiguidade nesse sentimento, em relação aos ricos, que vincula admiração e ressentimento. A suposta superioridade moral da classe média dá a sua clientela tudo aquilo que ela mais deseja: o sentimento de representarem o melhor da sociedade. Não só a classe que merece o que tem por esforço próprio, conforto que a falsa ideia da meritocracia propicia; mas, também, a classe que tem algo que ninguém tem, nem os ricos, que é a certeza de sua perfeição moral. (SOUZA, 2017, p.153)
}

Desta feita, a noção de classe média abarca mais que a faixa de renda, mas, também uma noção de capitais herdados e bem trabalhados, bem como, uma noção de moral e de merecimento que produz em si um imaginário de superioridade sobre as demais classes, por outro lado, aponta uma relação de ambivalência em relação aos ricos, na medida em que os invejam à eles querem se perfilar, no que os torna propícios a manipulação e a adoção de certos valores antidemocráticos e antissociais das camadas endinheiradas que deles se utilizam para impor suas preferências, criando alianças que tem em comum o preconceito e o ódio às classes subalternas. 
Diante deste quadro, o autor amarra com ineditismo estas questões ao utilizá-las como categorias de análise para compreender o fenômeno da Lava Jato. Tendo em vista, que ao apontar conceitos como o patrimonialismo, populismo e a noção de homem cordial, percebe instrumentação destes conceitos pela elite econômica brasileira como forma de esconder a verdadeira corrupção, bem como, para "opacizar" o elemento fundante da sociedade brasileira que a sua mentalidade escravocrata, materializada no ódio ao pobre, assim como uma noção vil, no qual o Estado e visto como corrupto, em detrimento do mercado virtuoso. Ao iluminar este debate, Jessé Souza, demonstra como a imprensa brasileira e em particular a Rede Globo em favor da elite financeira - esta verdadeira corruptora do Estado - se utilizam deste ideário conservador, como forma de descaracterizar e combater os inimigos das elites econômicas, jogando com o preconceito, o ódio aos pobres e o moralismo da classe média.

\begin{abstract}
Essas são as frações mais suscetíveis à imprensa e a seu papel de articular e homogeneizar um discurso dominante para além das idiossincrasias individuais. O que a grande empresa de imprensa vende a seu público cativo é essa tranquilidade das certezas fáceis, o que torna o moralismo cínico da imprensa - que nunca tematiza seu próprio papel nos esquemas de corrupção - o arranjo de manipulação política perfeito para esses estratos sociais. É esse compartilhamento afetivo e emocional, já advindo da força da socialização familiar anterior, que faz com que essas pessoas procurem o tipo de capital cultural mais afirmativo da ordem social. Nele o capataz da elite, que ajuda a reproduzir na realidade cotidiana todos os privilégios que estão ganhando, está em casa. (SOUZA, 2017, p.178)
\end{abstract}

O que o autor faz ao aludir estas questões é demonstrar como esta " influência continuada dessa leitura ( reforçadas pela imprensa e teorias conservadoras - grifo meu) na cabeça das pessoas nos faz de tolos.”, no que a Lava Jato, pela sua seletividade e a perseguição preferencial ao Partido dos Trabalhadores (PT) e ao seu líder Lula. Perseguição esta que levou ao Impeachment da Presidenta Eleita Dima Rousseff, ao encarceramento do ex-Presidente Lula e, segundo o autor ao efeito mais devastador, que foi a criminalização da ideia de igualdade social o princípio de que deveria se constituir como o de maior relevância para qualquer sociedade. Tudo em nome do combate à “corrupção dos tolos" que segundo Souza se caracteriza, por um combate ao "aviãozinho do narcotráfico", enquanto que a "a boca de fumo e o seu patrão" permanecem intocados.

No que aponta que:

Se compararmos nosso capitalismo com o narcotráfico, o político corrupto é o aviãozinho do tráfico, quem fica com as sobras; a boca de fumo que faz o dinheiro grande é o mercado da rapina selvagem que temos aqui. O conceito de patrimonialismo serve, precisamente, para encobrir os interesses organizados no mercado, que funcionam para se apropriar da riqueza social, já que a noção de privado é absurdamente pessoalizada, permitindo todo tipo de manipulação. A real função da noção de patrimonialismo é fazer o povo de tolo e manter a dominação mais tosca e abusiva de um mercado desregulado completamente invisível. (SOUZA-2017, p.209) 
O que se vê segundo a concepção é a construção de um engodo que visa sob muitos aspectos é a manutenção do establishment em detrimento do interesse coletivo, que ludibriado pela elite do atraso, isto é, dos grupos de interesse advindos do mercado, tanto nacional quanto internacional, com o apoio da grande mídia e a manipulam os interesses dos diversos grupos da sociedade, impondo seus interesses como se coletivo fossem, no intuito não só de usufruir e apropriar-se daquilo que pertence à todos, mas, também de impor uma lógica desumana as populações mais pobre em nome do rentismo.

Deste modo:

\begin{abstract}
A elite do atraso e seu braço midiático fazem parte, portanto, do mesmo esquema de depenar a população em seu benefício. É o que explica a constante necessidade de criar espantalhos para desviar a atenção do público do que lhe é surrupiado e explicar a penúria que seu saque provoca por outras causas. O espantalho perfeito é a corrupção dos tolos só da política, quando esses são meros lacaios de quem financia sua eleição para que protejam seus privilégios no mercado. Usa-se o desconhecimento da população, provocado pela distorção sistemática da realidade produzida pela própria mídia, para manipulá-la ao sabor da conjuntura que convém à elite do atraso. Quem comanda o assalto à população é a fração financeira do capital e da propriedade por meio de uma dívida pública que só cresce e pelo mecanismo de transferência de renda via juros e controle do orçamento público. Como as outras frações dos proprietários, como a indústria, o comércio e o agronegócio, retiram o lucro grande também da especulação financeira, isso explica que o comando de todo o processo econômico e político seja exercido pela fração dos rentistas. (SOUZA, 2017, p.229230)
\end{abstract}

Isto é, o engodo do combate à corrupção dos tolos, por fim tem como interesse apenas, o ataque não, apenas ao Estado puro e simples, mas, ao Estado de Direito e aos princípios ao qual ele representa. Ataque que tem como fim único a apropriação, espoliação e desconstrução deste em nome do interesse de grupos privados, do grande mercado e da grande mídia.

Diante de quadro tão pessimista o autor finaliza apontando que o primeiro passo para resolver tal situação é "reconhecermos que todos fomos feitos de tolos" e buscar na união a força necessária, para suplantar o estado de coisas que hora se agiganta frente a todos.

Assim, bem mais que uma análise de conjuntura política ou mesmo uma leitura panfletária, como pode parecer à primeira vista ao leitor comum, é uma obra de profunda análise e reflexão sociológica, que coloca em xeque visões cristalizadas sobre a sociedade brasileira de maneira bastante sólida e alicerçada, que decodifica de forma sistemática e heráldica os símbolos e os esquemas analíticos que tornam opacas diversas questões sociais importantes para a compreensão da crise enfrentada, bem como, enfrenta as rugosidades e vezos históricos, construindo um repertório eficaz para desconstrução e deslocamento das barreiras intelectuais apontadas no discorrer da obra. 